\title{
PERAN KOMITMEN ORGANISASIONAL MEMEDIASI PENGARUH BUDAYA ORGANISASI TERHADAP ORGANIZATIONAL CITIZENSHIP BEHAVIOR
}

\author{
I Putu Gede Ari Setyawan ${ }^{1}$ \\ Anak Agung Ayu Sriathi ${ }^{2}$ \\ ${ }^{1,2}$ Fakultas Ekonomi dan Bisnis Universitas Udayana (Unud), Bali, Indonesia \\ email: tudearisetyawan@gmail.com
}

\begin{abstract}
ABSTRAK
Tujuan penelitian ini adalah untuk mengetahui peran komitmen organisasional dalam memediasi pengaruh budaya organisasi terhadap organizational citizenship behavior (OCB). Penelitian ini dilakukan pada Dinas Penanaman Modal dan PTSP Kabupaten Badung. Jumlah sampel yang digunakan dalam penelitian ini sebanyak 135 pegawai. Teknik pengambilan sampel dilakukan dengan sampling jenuh. Teknik analisis yang digunakan adalah analisis jalur (path analysis). Hasil penelitian menunjukkan bahwa budayaorganisasi berpengaruh positif dan signifikan terhadap organizational citizenship behavior (OCB), budaya organisasi berpengaruh positif dan signifikan terhadap komitmen organisasional, komitmen organisasional berpengaruh positif dan signifikan terhadap organizational citizenship behavior (OCB), serta komitmen organisasional secara positif dan signifikan memediasi budaya organisasi terhadap organizational citizenship behavior (OCB) pada Dinas Penanaman Modal dan PTSP Kabupaten Badung. Upaya meningkatkan perilaku organizational citizenship behavior (OCB) pada pegawai, organisasi hendaknya mampu meningkatkan budaya organisasi dengan cara meningkatkan ketenangan di dalam lingkungan kerja.

Kata kunci: Budaya Organisasi, Komitmen Organisasional, Organizational Citizenship Behavior (OCB).
\end{abstract}

\begin{abstract}
The purpose of this study was to determine the role of organizational commitment in mediating the influence of organizational culture on organizational citizenship behavior $(O C B)$. This research was conducted at the Investment Office and PTSP in Badung Regency. The number of samples used in this study were 135 employees. The sampling technique is done by saturated sampling. The analysis technique used is path analysis. The results showed that organizational culture had a positive and significant effect on organizational citizenship behavior $(O C B)$, organizational culture had a positive and significant effect on organizational commitment, organizational commitment had a positive and significant effect on organizational citizenship behavior $(O C B)$, and organizational commitment positively and significantly mediated culture organization of organizational citizenship behavior (OCB) at the Badung Regency Investment and PTSP Office. Efforts to improve organizational citizenship behavior $(O C B)$ on employees, organizations should be able to improve organizational culture by increasing calm in the work environment.

Keywords: Organizational Culture, Organizational Commitment, Organizational Citizenship Behavior (OCB).
\end{abstract}




\section{PENDAHULUAN}

Suatu organisasi di dalam usahanya untuk mencapai tujuan yang telah direncanakan sangat tergantung pada berbagai faktor yang mempengaruhinya. Faktor yang secara umum bisa mempengaruhi kemajuan dari suatu organisasi adalah peran dari sumber daya manusia yang dimiliki, perilaku ekstra dan keefektifan dalam bekerja. Menurut Ardana dkk. (2012:3) sumber daya manusia adalah harta yang paling berharga dan paling penting dimiliki oleh suatu organisasi atau perusahaan, karena keberhasilan organisasi sangat ditentukan oleh unsur manusia. Tentunya peran perilaku ekstra yang tidak terdeskripsi secara formal (extra role) sangat dibutuhkan untuk bisa membantu mendorong kemajuan dari organisasi dan perilaku ekstra ini sering disebut sebagai Organizational Citizenship Behavior. Menurut Mira (2012), peran yang dimainkan oleh pegawai dalam organisasi dapat memberikan sesuatu yang berharga bagi organisasi itu sendiri, terlebih jika organisasi tersebut mampu memberdayakan orang-orang didalamnya secara efektif dan efisien, maka tidak diragukan lagi organisasi tersebut dapat mencapai tujuannya. Davoudi (2010) menyatakan bahwa dalam setiap perusahaan, sumber daya manusia merupakan sumber dayayang paling vital yang dimiliki perusahaan maupun organisasi.

Mengelola SDM yang baik, dimana pemimpin serta bagian yang menangani SDM harus mengerti masalah dengan manajemen SDM dengan baik pula (Widodo, 2015). Mempunyai pegawai yang bersedia menuangkan segenap kemampuannya demi kepentingan organisasi adalah harapan bagi semua organisasi atau perusahaan. Pegawai yang memiliki tanggung jawab atas pekerjaan yang dilakukannya, diharapkan dapat memberikan penghargaan atas prestasi yang dicapai oleh pegawainya. Setiap organisasi cenderung berusaha menemukan dan melaksanakan struktur organisasi yang memungkinkan SDM yang kompeten dan berkualitas sehingga diperoleh hasil kerja yang diharapkan, namun kenyataan yang terjadi adalah organisasi tidak sesuai dengan apa yang diharapkan.

Organisasi yang berhasil menumbuhkan pegawai yang memiliki sifat mampu melakukan pekerjaannya lebih dari sekedar pekerjaan formal mereka yang mampu memberikan kinerja yang baik melebihi harapan dari suatu organisasi atau perusahaan. SDM tidak hanya cukup melakukan tugasnya masing-masing sesuai dengan job description mereka, pegawai harus memiliki perilaku ekstra peran yang dapat memberi pengaruh positif demi kemajuan organisasi. Perilaku yang dapat meningkatkan produktivitas pegawai dalam organisasi yang disebutkan dalam penelitian Harper (2015) adalah perilaku extra-role atau disebut juga perilaku organizational citizenship behavior(OCB).

Organizational citizenship behavior (OCB) adalah perilaku secara sukarela dimana bukan bagian dari tugas yang sudah ditetapkan dan tidak dihargai secara langsung (Pourkiani et al., 2014). Menurut Lakshimi dan Simartama (2015) juga menyatakan bahwa OCB adalah suatu perilaku positif individu sebagai anggota organisasi dalam bentuk kesediaan secara sadar dan sukarela untuk bekerja dan memberikan kontribusi pada organisasi lebih dari pada tuntutan yang secara formal dalam organisasi yang mendukung berfungsinya organisasi secara efektif. Menurut Rauf (2014) OCB merupakan tindakan perilaku individu yang bebas, yang tidak secara langsung diakui oleh sistem pemberian penghargaan dalam fungsi efektif 
suatu organisasi.

Stanley (2013) menyatakan bahwa OCB ditandai dengan usaha dalam bentuk apapun yang dilakuan berdasarkan kebijaksanaan pegawai yang memberikan manfaat bagi organisasi tanpa mengharapkan imbalan apapun. Contoh dari pegawai yang memiliki perilaku OCB adalah berinisiatif membantu rekan kerja, patuh terhadap aturan-aturan dan prosedur di organisasi, tidak membuang-buang waktu kerja, mengajukan ide atau saran yang berguna untuk perusahaan, mampu bekerja lebih baik tanpa pengawasan pimpinan dan perilaku ini biasanya ditandai dengan spontanitas serta ketulusan (Maria et al., 2015).

Penelitian ini dilakukan di Dinas Penanaman Modal dan Pelayanan Terpadu Satu Pintu (PTSP) Kabupaten Badung yang beralamat di Jalan Raya Sempidi, Mengwi Kabupaten Badung. Kepala Dinas Penanaman Modal dan Pelayanan Terpadu Satu Pintu Kabupaten Badung dalam Pelayanan Perizinan dan Non Perizinan. Dinas Penanaman Modal dan Pelayanan Terpadu Satu Pintu beserta dengan tugas serta fungsinya. Terwujudnya Badan Pelayanan Perizinan Terpadu Satu Pintu adalah dalam rangka melayani berbagai jenis perizinan dan non perizinan di 1 (satu) pintu, serta transparan dalam hal mekanisme, persyaratan, biaya dan waktu. Hal ini sejalan dengan tujuan dan sasaran untuk mewujudkan pelayanan publik yang cepat, tepat, murah, mudah, transparan, pasti dan terjangkau, serta mampu meningkatkan hak-hak masyarakat dalam pelayanan publik.

Berdasarkan hasil prariset dengan menggunakan metode observasi dan wawancara awal pada lima orang pegawai di bidang perizinan kesejahteraan rakyat dan non perizinan, lima orang pegawai di bidang program dan informasi, serta lima orang pegawai di bidang pengaduan dan pelaporan ditemukan beberapa masalah yang terjadi terkait dengan lima indikator OCB pada Dinas Penanaman Modal dan Pelayanan Terpadu Satu Pintu (PTSP) Kabupaten Badungdiantaranya yaitu, empat orang pegawai yang telah selesai melakukan pekerjaan namun tidak mau membantu rekan kerja yang memiliki pekerjaan yang lebih maupun rekan kerja yang tidak masuk bekerja atau sedang sakit, dan mereka cenderung untuk beristirahat di luar ruangan. Kemudian sebanyak lima orang pegawai masih memiliki ego yang tinggi atau ketidakpedulian dengan setiap pegawai masing-masing bidang dengan bidang yang lain dalam berkoordinasi mengenai pekerjaan sehingga dapat mempengaruhi kinerja dari pegawai tersebut. Kemudian sebanyak dua belas orang pegawaiyang datang terlambat sehingga tidak bisa mengikuti apel pagi. Masih terdapat pegawai yang datang hanya absen namun tidak ada diruangannya tanpa ada kejelasan dari pegawai itu sendiri. Terdapat tiga orang pegawai yang pulang mendahului dari jam pulang kantor yang sudah ditetapkan oleh organisasi.

Masalah-masalah tersebut jika tidak diselesaikan dengan baik akan menyebabkan suatu pekerjaan tidak cepat terselesaikan, karena kantor yang sifatnya memberikan pelayanan dan pembinaan dalam hal ini perizinan dan non perizinan yang ada di Badung memerlukan pegawai yang memiliki perilaku ekstra, sigap dan cekatan. Berdasarkan hasil metode observasi yang telah dilakukan, masalah yang ditemukan pada kantor tersebut disebabkan akibat kurang senangnya pegawai dalam menyelesaikan pekerjaan dengan kerjasama tim dan juga pegawai kurang merasakan ketenangan saat melakukan aktivitas kerja pada kantor serta karakteristik yang dimiliki oleh masing-masing individu berbeda sehingga inisiatif 
untuk melakukan pekerjaan maupun membantu rekan kerja tidak sama pada setiap individu dan juga akibat budaya organisasi yang masih terlalu lemah yang membuat pegawai menjadikan perilaku diatas menjadi sebuah kebiasan dan tidak memiliki inisiatif serta agresif dalam meningkatkan kinerjanya, serta komitmen yang dimiliki pegawai masih kurang maksimal sehingga menyebabkan rendahnya perilaku OCB pegawai dalam organisasi.

Rendahnya OCB dapat dipengaruhi oleh beberapa faktor yang dapat menyebabkan rendahnya perilaku OCB yaitu komitmen organisasional merupakan identifikasi rasa, keterlibatan, dan loyalitas yang ditampakkan oleh pegawai terhadap organisasi yang menjadi tempatnya untuk mengabdi dan bekerja menurut Suwatno dan Priansa (2014:232). Rendahnya komitmen organisasi, mencerminkan kurangnya tanggung jawab pegawai dalam menjalankan tugasnya. Mempersoalkan komitmen sama dengan mempersoalkan tanggung jawab. Menurut Riady (2009) pegawai yang memiliki komitmen rendah dapat ditunjukkan dengan tidak adanya semangat kerja pegawai. Pentingnya membangun OCB dalam lingkungan kerja, tidak lepas dari bagaimana komitmen yang ada dalam diri pegawai untuk memajukan organisasinya. Komitmen yang tinggi menjadikan individu peduli dengan nasib organisasi dan berusaha menjadikan organisasi ke arah yang lebih baik, sehingga dengan adanya komitmen yang tinggi akan mempengaruhi pegawai untuk melakukan perilaku OCB. Untuk meningkatkan OCB pegawai maka sangat penting bagi organisasi untuk mengetahui apa yang menyebabkan timbulnya atau meningkatnya OCB. Menurut (Siders et al., 2009) dalam Purnamie (2014), meningkatnya perilaku OCB dipengaruhi oleh dua faktor utama yaitu faktor yang berasal dari diri karyawan (internal) seperti moral, motivasi, komitmen, rasa puas/kepuasan kerja, sikap postitif sedangkan faktor yang berasal dari luar karyawan (eksternal) seperti sistem manajemen, kepemimpinan, budaya perusahaan dll. Secara terperinci Alizadeh et al . (2012) mengatakan bahwa terdapat beberapa variabel yang mempengaruhi perilaku OCB karyawan, diantaranya adalah kejelasan peraturan, kepemimpinan, komitmen organisasional, keadilan organisasi, dan sifat setiap individu. Berdasarkan pernyataan tersebut, maka dapat dikatakan bahwa ada beberapa faktor penting yang dapat meningkatkan OCB diantaranya adalah budaya organisasi dan komitmen organisasi.

Dalam meningkatkan komitmen pegawai dalam bekerja dibutuhkan budaya organisasi yang mampu memberikan dampak positif bagi OCB dan komitmen organisasional disuatu organisasi atau perusahaan. Oemar (2013) menyatakan bahwa semakin positif pegawai dalam menilai budaya organisasi dan semakin ia terlibat dalam organisasi, maka kecenderungan OCB akan meningkat juga. Budaya organisasi merupakan suatu sistem berbagi arti yang dilakukan para anggota yang membedakan suatu organisasi dari organisasi lain (Robbins dan Judge, 2015: 355). Arifin (2015) menyatakan bahwa budaya organisasi adalah semua keyakinan, perasaan, perilaku dan simbol-simbol yang mencirikan suatu organisasi. Miharty (2013) mendefinisikan bahwa budaya organisasi mengacu pada pola asumsi dasar bersama dan kelompok telah dapat memecahkan masalah yang diadopsi dari eksternal dan integrasi internal yang telah bekerja cukup baik untuk dipertimbangkan. Menurut Xiaoming dan Junchen (2012) organisasi sebagai pola pemecahan masalah internal dan eksternal yang diterapkan secara konsisten bagi 
suatu kelompok organisasi. Dalam meningkatkan kinerja pegawai maka tingkat komitmen yang dimiliki pegawai itu penting sehingga dengan komitmen pegawai yang tinggi perilaku OCB akan semakin kuat dalam menunjang kemajuan suatu organisasi serta budaya organisasi yang diterapkan mampu memberikan dampak yang baik terhadap OCB didalam organisasi.

Peran komitmen organisasional memediasi pengaruh budaya organisasi terhadap organizational citizenship behavior (OCB) dapat dilihat dari hasil Penelitian yang dilakukan oleh Wijaya dan Ahyar (2017) yang mendapatkan hasil bahwa budaya organisasi dan dukungan organisasi terhadap OCB dengan Komitmen Organisasional sebagai variabel mediasi berpengaruh positif dan signifikan. Sedangkan menurut penelitian Khan dan Rashid (2015) menghasilkan sebuah kesimpulan bahwa Komitmen Organisasional merupakan variabel mediasi yang baik untuk mengetahui hubungan antara budaya organisasi, gaya kepemimpinan dan keadilan organisasi terhadap OCB, karena pada penelitian ini Komitmen Organisasional memiliki pengaruh positif dan signifikan terbesar bila dibandingkan dengan variabel yang lainnya.

Budaya organisasi berperan sebagai hal penting dalam sebuah perusahaan yang akan menentukan bagaimana karyawan berperilaku di dalamnya. Keberhasilan pembentukan perilaku karyawan yang positif dalam perusahaan adalah cerminan berhasilnya penerapan budaya organisasi yang baik, hal tersebut akan mempengaruhi perilaku in-role ataupun perilaku extra-role.

Teori ini didukung dengan peneitian yang dilakukan Arifin (2015) menemukan bahwa Budaya Organisasi berpengaruh positif terhadap Organizational Citienship Behavior. Menurut Penelitan Xiaoming dan Junchen (2012) mendapat hasil budaya organisasi berpengaruh positif dan signifikan terhadap OCB. Menurut penelitian Oemar (2013) menyatakan bahwa semakin positif pegawai dalam menilai budaya organisasi dan semakin ia terlibat dalam organisasi yang ada di instansinya, maka kecenderungan organizational citizenship behavior akan meningkat pula. Menurut penelitian Cahyono dkk. (2016) menyatakan bahwa hasil pengujian budaya organisasi menunjukkan pengaruh yang signifikan terhadap organizational citizenship behavior (OCB) Tenaga medis pada RSU Kaliwates Jember. Menurut Maulani dkk. (2015) hasil dari penelitiannya diketahui terdapat pengaruh yang signifikan antara budaya organisasi terhadap organizational citizenship behavior (OCB). Penelitian dari Setyawati (2012) juga menyatakan bahwa budaya organisasi memberikan pengaruh signifikan dan positif terhadap OCB pegawai PT. PLN (Persero) Area Pelayanan dan Jaringan (APJ) Purwoketo. Penelitian Wijaya dan Ahyar (2017) juga menyatakan bahwa budaya organisasi berpengaruh positif dan signifikan terhadap organizational citizenship behavior. Hal ini dapat dilihat dari semakin baik atau kuat budaya organisasiakan semakin meningkatkan organizational citizenship behavior (OCB). Penelitian Rongga et al. (2001) adanya hubungan yang positif antara budaya organisasi dengan Organizational Citizenship Behavior (OCB), khususnya diperoleh hasil bahwa budaya organisasi yang lebih berorientasi pada pekerja, lebih terbuka dan lebih bersifat konsultatif, pada umunnya dihubungkan dengan sikap yang lebih positif, walaupun hubungan antara budaya dengan Organizational Citizenship Behavior (OCB) tidak terlalu kuat. Erkutlu (2011) menyatakan bahwa budaya organisasi 
mampu menjelaskan dan memberikan peranan yang penting dalam hubungan antara keadilan organisasi dan Organizational Citizenship Behavior (OCB) dalam suatu organisasi. Penelitian yang dilakukan Mohanty dan Rath (2012) menyatakan bahwa semua dimensi budaya organisasi mempunyai hubungan positif signifikan terhadap organizational citizenship behavior. Dalam penelitian ini dikatakan bahwa budaya organisasi dalam kerangka tertentu dapat membentuk perilaku OCB diantara karyawan.

Berdasarkan penelitian terdahulu dan studi empiris yang telah dipaparkan maka hipotesis dalam penelitian ini adalah:

$\mathrm{H}_{1}$ : Budaya organisasi berpengaruh positif dan signifikan terhadap organizational citizenship behavior (OCB).

Budaya organisasi sering dijelaskan sebagai cara kita melakukan hal-haldi lingkungan organisasi dan apa yang terjadi dan apa yang tidak. Menurut Liu (2009) komitmen organisasi karyawan adalah tentang kesetiaan seorang karyawan kepada organisasi, kesediaan untuk mengerahkan usaha atas nama organisasi, tingkat tujuan dan nilai kongruensi antara karyawan dan organisasi, dan keinginan karyawan untuk tetap dipekerjakan oleh organisasi.

Teori ini didukung dengan peneitian yang dilakukan oleh Wibawa dan Putra (2018) dengan judul penelitian pengaruh budaya organisasi terhadap komitmen organisasional dimediasi oleh kepuasan kerja studi pada PT. Bening Badung Bali mendapat hasil bahwa budaya organisasi berpengaruh positif terhadap komitmen organisasional. Budaya organisasi memiliki dampak yang kuat pada perilaku pegawai yang diikuti dengan efektivitas organisasi dan akan memudahkan manajer dalam memahami organisasi dimana mereka bekerja tidak hanya untuk perumusan kebijakan dan prosedur, tetapi untuk memahami perilaku manusia dan pemanfaatan sumber daya manusia dengan cara yang terbaik (Khan dan Rashid, 2015). Menurut Liu (2009) komitmen organisasional pegawai tentang kesetiaan seorang pegawai kepada organisasi, kesediaan untuk mengerahkan usaha atas nama organisasi, tingkat tujuan dan nilai kongruensi antara pegawai dan organisasi, dan keinginan pegawai untuk tetap dipekerjakan oleh organisasi. Hasil analisis data pada penelitian Liu (2009) menunjukkan bahwa pada dimensi budaya organisasi, ditemukan anteseden yang memiliki efek terhadap Komitmen Organisasional, dimana dimensi budaya menunjukkan berbagai tingkat pengaruh positif terhadap Komitmen Organisasional pegawai. Hasil penelitian yang dilakukan oleh Alfiana dan Puspasari (2015) mendapat hasil bahwa ada pengaruh yang positif antara budaya organisasi terhadap komitmen organisasi karyawan PT. Sinar Sosro Surabaya. Hasil yang sama juga diperoleh oleh Permatasari dan Supartha (2017) bahwa budaya organisasi memiliki pengaruh yang signifikan terhadap komitmen organisasional karyawan. Lanjar dkk. (2017) mendapatkan hasil yang sama bahwa budaya organisasi berpengaruh positif terhadap komitmen organisasional. Alvi et al. (2014) meneliti tentang pengaruh budaya organisasi terhadap komitmen organisasional dan kepuasan kerja menunjukan hasil bahwa budaya organisasi berpengaruh positif terhadap komitmen organisasional. Li Yueh Chen (2004) menyatakan bahwa budaya organisasi dan gaya kepemimpinan berpengaruh signifikan positif terhadap komitmen organisasional, kepuasan kerja dan kinerja karyawan. Zain et al. (2009) menyatakan seluruh dimensi budaya organisasi 
(kerjasama tim, komunikasi, penghargaan, pelatihan, dan pengembangan) memilki pengaruh positif signifikan terhadap komitmen organisasional. Menurut Antonio dan Miguel (2013), adanya penyesuaian yang lebih baik antara persepsi budaya organisasi dan nilai- nilai yang telah dianut organisasi memiliki hubungan yang positip terhadap komitmen organisasional.

Berdasarkan penelitian terdahulu dan studi empiris yang telah dipaparkan maka hipotesis dalam penelitian ini adalah:

$\mathrm{H}_{2}$ : Budaya Organisasi berpengaruh positif dan signifikan terhadap Komitmen

Organisasional.

Penelitian sampai dengan saat ini membuktikan bahwa tiga komponen komitmen organisasi yang terdiri dari komitmen bersinambung, afektif dan normatif ketiganya berpengaruh dan memiliki hubungan positif terhadap OCB. Hal tersebut didapatkan dari penelitian Bakhshi et al. (2011) terhadap karyawan dalam perusahaan sektor publik di India. Namun pada penelitian itu pula disebutkan bahwa variabel demografi yang meliputi umur, status perkawinan, jenis kelamin sama sekali tidak berpengaruh terhadap OCB. Qamar (2012) menyebutkan bahwa dimensi OCB secara positif dan signifikan dipengaruhi oleh kepuasan kerja dan komitmen organisasi. Namun, komitmen organisasi memiliki pengaruh lebih kuat terhadap OCB. Hal tersebutlah yang kemudian dapat dikatakan menjadi dasar bahwa OCB (Organizational Citizenship Behavior) dapat dipengaruhi oleh komitmen organisasi.

Teori ini didukung dengan peneitian yang dilakukan oleh Gautam et al. (2005) mendapatkan hasil bahwa Komitmen Organisasional memiliki pengaruh positif signifikan terhadap Organizational Citizenship Behavior. Hasil penelitian yang dilakukan oleh Chen dan Francesco (2003) mendapatkan bahwa komitmen memiliki pengaruh positif signifikan terhadap OCB. Menurut penelitian Rahmawati (2013) ditemukan bahwa Komitmen Organisasional memberikan pengaruh yang positif terhadap OCB. Penelitian yang dilakukan oleh Sani (2013) yang melibatkan 74 pegawai PT. Bank Syariah Malang menemukan bahwa Komitmen Organisasional berpengaruh positif terhadap OCB. Komitmen pegawai yang besar akan lebih sering berbicara secara positif tentang perusahaannya, membantu individu lain dan jauh melebihi harapan normal dalam pekerjaan mereka, selain itu pegawai melakukan pekerjaan dilandasi keinginan dari diri sendiri atau tanpa paksaan (Devi dan Adnyani, 2015). Ratnaningsih (2013) dalam penelitiannya menemukan bahwa komitmen memberikan pengaruh yang positif terhadap OCB. Penelitian yang dilakukan Rini dkk. (2013) menunjukkan bahwa Komitmen Organisasional memiliki pengaruh positif signifikan terhadap OCB. Maria et al. (2015), Qamar (2012) dan Liu (2009) melakukan penelitian dan menemukan bahwa komitmen organisasi secara signifikan terkait dengan dimensi OCB. Komitmen organisasi adalah kemauan untuk mengerahkan usaha ekstra untuk kepentingan organisasi, dan keinginan yang kuat untuk mempertahankan keanggotaan dalam organisasi (Zeinabadi dan Salehi (2011). Pada dasarnya komitmen organisasi dapat menjadi prediktor untuk OCB sebagai hasil dari Zeinabadi dan Salehi (2011). Moorman et al. (1993) yang menyatakan bahwa komitmen organisasi secara langsung mempengaruhi OCB. Rehan dan Islam (2013) dalam penelitiannya mendapatkan hasil bahwa ketiga bentuk komitmen 
mempengaruhi OCB secara signifikan.

Berdasarkan penelitian terdahulu dan studi empiris yang telah dipaparkan maka hipotesis dalam penelitian ini adalah:

$\mathrm{H}_{3}$ : Komitmen Organisasional berpengaruh positif dan signifikan terhadap organizational citizenship behavior (OCB).

Keberhasilan perusahaan dalam menerapkan budaya organisasi diantara pegawai-pegawai akan mempengaruhi setiap tindakan maupun perilaku positif pegawai, baik perilaku in-role ataupun perilaku extra-role dan juga akan mengantarkan organisasi pada kesuksesan. Teori ini didukung dengan peneitian yang dilakukan oleh Wijaya dan Ahyar (2017) hasil bahwa budaya organisasi dan dukungan organisasi terhadap OCB dengan Komitmen Organisasional sebagai variabel mediasi berpengaruh positif dan signifikan. Sedangkan menurut Akhtar dalam Sanhaji dkk, (2016) menyatakan bahwa budaya organisasi dapat membantu meningkatkan komitmen para karyawan. Kim (2014) menyebutkan bahwa komitmen afektif secara penuh memediasi antara variabel budaya organisasi dan organizational citizenship behavior pada penelitian yang dilakukan di sektor publik Korea Selatan. Mohanty dan Rath (2012) mengatakan karyawan yang merasa bahwa budaya organisasi yang ada pada perusahaan mendukung setiap nilai atau tujuan individu mereka akan lebih nyaman dengan perusahaan sehingga ia akan mendukung setiap rencana-rencana perusahaan dan kemungkinan menunjukkan perilaku yang berada di luar deskripsi pekerjaannya juga semakin kuat. Penelitian yang dilakukan oleh Nandan dan Abdul (2015) menyatakan bahwa komitmen organisasi memediasi pengaruh budaya organisasi terhadap organizational citizenship behavior. Komitmen organisasional mempunyai pengaruh mediasi atau intervening variabel keadilan dan persepsi dukungan organisasi terhadap perilaku OCB dikarenakan jika anggota dalam organisasi memiliki komitmen yang tinggi baik secara afektif, normatif ataupun kontinuan, akan terbentuk hubungan positif antar anggota terhadap organisasi tempat mereka tinggal (Fitriasmi, 2010). Hal ini akan mengakibatkan anggota merasa terikat dengan organisasi yang mendorong kecintaanya terhadap organisasi yang kemudian sukarela melakukan perilaku diluar tanggung jawab pekerjaan mereka (extra role) guna bagian dalam memajukan organisasi tempat mereka tinggal terlepas tinggi rendahnya persepsi dukungan organisasi dan keadilan organisasi yang dirasakan oleh anggota organisasi. Williams et al. (2007) menyimpulkan bahwa ketika komitmen organisasi telah tertanam dalam suatu pola pikir karyawan akan lebih mudah bagi mereka untuk melakukan OCB. Menurut Harwiki (2013), budaya organisasi dan komitmen organisasional berpengaruh positif dan signifikan terhadap OCB. Penelitian Khan dan Rashid (2015) menghasilkan sebuah kesimpulan bahwa komitmen organisasional merupakan variabel mediasi yang baik untuk mengetahui hubungan antara budaya organisasi, gaya kepemimpinan dan keadilan organisasi terhadap OCB, karena pada penelitian ini komitmen organisasional memiliki pengaruh positif dan signifikan terbesar bila dibandingkan dengan variabel yanglainnya.

Berdasarkan penelitian terdahulu dan studi empiris yang telah dipaparkan maka hipotesis dalam penelitian ini adalah: 
$\mathrm{H}_{4}$ : Budaya Organisasi terhadap Organizational Citizenship Behavior berpengaruh positif dengan Komitmen Organisasional sebagai variabel mediasi.

\section{METODE PENELITIAN}

Penelitian ini bertempat pada Dinas Penanaman Modal dan Pelayanan Terpadu Satu Pintu Kabupaten Badung yang beralamat di Jalan Raya Sempidi, Mengwi, Kabupaten Badung, Bali. Penelitian ini dilakukan pada Dinas Penanaman Modal dan Pelayanan Terpadu Satu Pintu Kabupaten Badung karena belum banyak yang melakukan penelitian diinstansi tersebut, dan diduga terdapat masalah yang terkait dengan Organizational Citizenship Behavior(OCB). Objek penelitian dalam penelitian ini adalah komitmen organisasional, budaya organisasi dan organizational citizenship behavior (OCB).

Populasi yang digunakan dalam penelitian ini adalah seluruh pegawai PNS (tidak termasuk pimpinan atau atasan) yang bekerja pada Dinas Penanaman Modal dan Pelayanan Terpadu Satu Pintu Kabupaten Badung yang berjumlah 135 orang. Teknik pengambilan sampel dilakukan dengan sampling jenuh, yaitu dengan cara mengambil seluruh populasi sebagai sampel (Sugiyono, 2014). Teknik ini dipilih karena jumlah dari populasi tergolong kecil, sehingga seluruh populasi digunakan sebagai sampel dalam penelitian ini.

Teknik analisis data yang digunakan dalam penelitian ini adalah analisis jalur (Path Analysis). Ghozali (2013:249) mendefinisikan analisis jalur (path analysis) adalah perluasan dari analisis regresi linear berganda dalam memperkirakan hubungan kausalitas antara variabel yang telah ditetapkan sebelumnya berdasarkan teori. Teknik analisis jalur ini akan digunakan dalam menguji besarnya kontribusi yang dinyatakan oleh koefisien jalur pada setiap diagram jalur dari hubungan kausal atau sebab akibat yang tercipta dari variabel eksogen terhadap variabel endogen. Pada dasarnya perhitungan koefisien jalur membutuhkan perhitungan dari analisis korelasi dan regresi yang kemudian dituangkan dalam software berupa SPSS for windows version 24.0.

Berdasarkan hubungan-hubungan antar variabel secara teoritis tersebut, dapat dibuat model dalam bentuk diagram jalur (path). Model tersebut juga dapat dinyatakan dalam bentuk persamaan atau diagram jalur sehingga ada yang menamakan sistem simultan, atau juga ada yang menyebut model struktural.

Sub-struktural 1

$\mathrm{M}=\beta_{2} \mathrm{X}+\mathrm{e}_{1}$

Sub-struktural 2

$\mathrm{Y}=\beta_{1} \mathrm{X}+\beta_{3} \mathrm{M}+\mathrm{e}_{2}$

Keterangan :

$\mathrm{Y}=$ organizational citizenshipbehavior

$\mathrm{X} \quad$ = budaya organisasi 
$\mathrm{M}=$ komitmen organisasional

$\beta_{1}, \beta_{2}, \beta_{3}=$ koefisien regresi variabel

e $\quad=$ error

\section{HASIL DAN PEMBAHASAN}

Perhitungan koefisien jalur dilakukan dengan menggunakan software berupa SPSS for windows version 24.0, hasil dari pengolahan data untuk persamaan regresi 1 disajikan dalam Tabel 1. sebagai berikut:

Tabel 1.

Hasil Analisis Jalur Persamaan Regresi 1

\begin{tabular}{|c|c|c|c|c|c|c|}
\hline \multirow[t]{2}{*}{ Model } & & \multicolumn{2}{|c|}{$\begin{array}{l}\text { Unstandardized } \\
\text { Coefficients }\end{array}$} & \multirow{2}{*}{$\begin{array}{c}\text { Standardized } \\
\text { Coefficients } \\
\text { Beta }\end{array}$} & \multirow[t]{2}{*}{$\mathbf{T}$} & \multirow[t]{2}{*}{ Sig. } \\
\hline & & B & Std. Error & & & \\
\hline 1 & (Constant) & 0,525 & 0,382 & & 1,375 & 0,171 \\
\hline & Budaya organisasi & 0,803 & 0,089 & 0,615 & 8,987 & 0,000 \\
\hline
\end{tabular}

Sumber: Data diolah, 2020

Berdasarkan hasil analisis jalur persamaan regresi 1 seperti yang disajikan pada Tabel 1, maka dapat dibuat persamaan struktural sebagai berikut:

$$
\mathrm{M}=0,615 \mathrm{X}+\mathrm{e}_{1}
$$

Nilai koefisien regresi variabel budaya organisasi bernilai positif dengan nilai signifikansi uji t kurang dari 0,05. Hal ini menunjukkan bahwa variabel budaya organisasi memiliki pengaruh positif yang signifikan terhadap variabel komitmen organisasional. Besarnya pengaruh tersebut ditunjukkan oleh nilai determinasi total ( $R$ Square) sebesar 0,378 mempunyai arti bahwa sebesar 37,8 persen, variasi komitmen organisasional dipengaruhi oleh variasi budaya organisasi, sedangkan sisanya sebesar 62,2 persen, dijelaskan oleh faktor lain yang tidak dimasukan dalam model.

Tabel 2.

Hasil Analisis Jalur Persamaan Regresi 2

\begin{tabular}{|c|c|c|c|c|c|c|}
\hline \multirow[t]{2}{*}{ Model } & & \multicolumn{2}{|c|}{$\begin{array}{l}\text { Unstandardized } \\
\text { Coefficients }\end{array}$} & \multirow{2}{*}{$\begin{array}{c}\text { Standardized } \\
\text { Coefficients } \\
\text { Beta }\end{array}$} & \multirow[t]{2}{*}{$\mathbf{T}$} & \multirow[t]{2}{*}{ Sig. } \\
\hline & & B & Std. Error & & & \\
\hline \multirow[t]{3}{*}{1} & (Constant) & 1,191 & 0,170 & & 7,002 & 0,000 \\
\hline & Budaya organisasi & 0,427 & 0,050 & 0,486 & 8,521 & 0,000 \\
\hline & Komitmen org & 0,313 & 0,038 & 0,466 & 8,159 & 0,000 \\
\hline
\end{tabular}

Sumber: Data diolah, 2020

Berdasarkan hasil analisis jalur persamaan regresi 2 seperti yang disajikan pada Tabel 2, maka dapat dibuat persamaan struktural sebagai berikut:

$$
\mathrm{Y}=0,486 \mathrm{X}+0,466 \mathrm{M}
$$

Nilai koefisien regresi masing-masing variabel bebas bernilai positif dengan nilai signifikansi uji t kurang dari 0,05. Hal ini menunjukkan bahwa semua variabel 
bebas memiliki pengaruh positif yang signifikan terhadap variabel terikat. Besarnya pengaruh variabel bebas terhadap variabel terikat yang ditunjukkan oleh nilai determinasi total ( $R$ Square) sebesar 0,732 mempunyai arti bahwa sebesar 73,2 persen variasi organizational citizenship behavior (OCB) dipengaruhi oleh variasi budaya organisasi dan komitmen organisasional, sedangkan sisanya sebesar 26,8 persen dijelaskan oleh faktor lain yang tidak dimasukkan ke dalam model.

Berdasarkan model substruktur 1 dan substruktur 2, maka dapat disusun model diagram jalur akhir. Sebelum menyusun model diagram jalur akhir, terlebih dahulu dihitung nilai standar eror sebagai berikut:

$$
\begin{aligned}
& \mathrm{Pe}_{\mathrm{i}}=\sqrt{1-\mathrm{R}} \mathrm{i}^{2} \ldots \ldots \ldots \ldots \ldots \ldots \ldots \ldots \ldots \ldots \ldots \ldots \\
& \mathrm{Pe}_{1}=\sqrt{1-\mathrm{R}^{2}}=\sqrt{1-0,378}=\sqrt{0,622}=0,788 \\
& \mathrm{Pe}_{2}=\sqrt{1-\mathrm{R}^{2}}=\sqrt{1-0,732}=\sqrt{0,268}=0,517
\end{aligned}
$$

Berdasarkan perhitungan pengaruh error (Pei), didapatkan hasil pengaruh error $\left(\mathrm{Pe}_{1}\right)$ sebesar 0,788 dan pengaruh error $\left(\mathrm{Pe}_{2}\right)$ sebesar 0,517. Hasil koefisien determinasi total adalah sebagai berikut.

$$
\begin{aligned}
\mathrm{R}^{2} \mathrm{~m} & =1-\left(\mathrm{Pe}_{1}\right)^{2}\left(\mathrm{Pe}_{2}\right)^{2} \\
& =1-(0,788)^{2}(0,517)^{2} \\
& =1-(0,620)(0,267) \\
& =1-0,165=0,835
\end{aligned}
$$

Nilai determinasi total sebesar 0,835 mempunyai arti bahwa sebesar 83,5 persen variasi organizational citizenship behavior (OCB) pada Dinas Penanaman Modal dan PTSP Kabupaten Badung dipengaruhi oleh variasi budaya organisasi dan komitmen organisasional, sedangkan sisanya sebesar 16,5 persen djelaskan oleh faktor lain yang tidak dimasukkan ke dalam model.

Berdasarkan hasil analisis pengaruh budaya organisasi terhadap organizational citizenship behavior diperoleh nilai Signifikansi sebesar 0,000 dengan nilai koefisien beta 0,486 , dan nilai t sebesar 8,521. Nilai signifikansi 0,000 $<0,05$ mengindikasikan bahwa $\mathrm{H}_{0}$ ditolak dan $\mathrm{H}_{1}$ diterima. Hasil ini mempunyai arti bahwa budaya organisasi berpengaruh positif dan signifikan terhadap organizational citizenship behavior pada Dinas Penanaman Modal dan PTSP Kabupaten Badung.

Berdasarkan hasil analisis pengaruh budaya organisasi terhadap komitmen organisasional diperoleh nilai Signifikansi sebesar 0,000 dengan nilai koefisien beta 0,615, dan nilai t sebesar 8,987. Nilai signifikansi $0,000<0,05$ mengindikasikan bahwa $\mathrm{H}_{0}$ ditolak dan $\mathrm{H}_{2}$ diterima. Hasil ini mempunyai arti bahwa budaya organisasi berpengaruh positif dan signifikan terhadap komitmen organisasional pada Dinas Penanaman Modal dan PTSP Kabupaten Badung.

Berdasarkan hasil analisis pengaruh komitmen organisasional terhadap organizational citizenship behavior diperoleh nilai Signifikansi sebesar 0,000 dengan nilai koefisien beta 0,466 , dan nilai t sebesar 8,159 Nilai signifikansi 0,000 $<0,05$ mengindikasikan bahwa $\mathrm{H}_{0}$ ditolak dan $\mathrm{H}_{3}$ diterima. Hasil ini mempunyai 
arti bahwa komitmen organisasional berpengaruh positif dan signifikan terhadap organizational citizenship behavior pada Dinas Penanaman Modal dan PTSP Kabupaten Badung.

Tabel 3.

Pengaruh Langsung dan Pengaruh Tidak Langsung serta Pengaruh Total Budaya Organisasi (X), Komitmen Organisasional (M), dan Organizational Citizenship Behavior (Y)

\begin{tabular}{cccc}
\hline $\begin{array}{c}\text { Pengaruh } \\
\text { Variabel }\end{array}$ & $\begin{array}{c}\text { Pengaruh } \\
\text { Langsung }\end{array}$ & $\begin{array}{c}\text { Pengaruh Tidak Langsung Melalui } \\
\text { Komitmen Organisasional } \\
(\mathbf{M})\end{array}$ & $\begin{array}{c}\text { Pengaruh } \\
\text { Total }\end{array}$ \\
\hline $\mathrm{X} \rightarrow \mathrm{Y}$ & 0,486 & 0,226 & 0,772 \\
$\mathrm{X} \rightarrow \mathrm{M}$ & 0,615 & - & 0,615 \\
$\mathrm{M} \rightarrow \mathrm{Y}$ & 0,466 & - & 0,466 \\
\hline
\end{tabular}

Sumber: Data diolah, 2020

Berdasarkan hasil perhitungan diatas menunjukkan bahwa pengaruh langsung budaya organisasi terhadap organizational citizenship behavior adalah sebesar 0,486. Pengaruh langsung variabel budaya organisasi terhadap komitmen organisasional sebesar 0,615 . Pengaruh langsung variabel komitmen organisasional terhadap organizational citizenship behavior sebesar 0,466. Hal ini berarti bahwa variabel organizational citizenship behavior lebih besar dipengaruhi oleh variabel budaya organisasi dibandingkan komitmen organisasional. Sedangkan pengaruh tidak langsung variabel budaya organisasi terhadap organizational citizenship behavior melalui komitmen organisasional sebesar 0,226. Jadi pengaruh total variabel budaya organisasi terhadap organizational citizenship behavior melalui komitmen organisasional adalah sebesar 0,772.

Uji sobel digunakan dengan menguji kekuatan pengaruh tidak langsung variabel Budaya Organisasi (X) terhadap Organizational Citizenship Behavior (Y) melalui variabel Komitmen Organisasional (M). Pengaruh tidak langsung dihitung dengan cara mengalikan koefisien jalur X terhadap $M$ (a) dengan koefisien jalur $M$ terhadap Y (b) atau ab. Apabila nilai kalkulasi Z lebih besar dari 1,96 (dengan tingkat kepercayaan 95 persen), maka variabel komitmen organisasional dinilai secara signifikan memediasi hubungan antara variabel organizational citizenship behavior dan variabel budaya organisasi.

Penghitungan variabel mediasi menggunakan statistik uji sobel dihitung dengan rumus dibawah ini:

$$
\begin{aligned}
& \mathrm{Z}=\frac{a b}{\sqrt{b^{2} S a^{2}+a^{2} S b^{2}+S a^{2} S b^{2}}} \ldots \ldots \ldots \\
& \operatorname{Sig}=(1-\operatorname{NORMDIST}(\mathrm{Z})) 2))
\end{aligned}
$$

Keterangan:

$$
\begin{aligned}
& \mathrm{a}=0,803 \\
& \mathrm{~s}_{\mathrm{a}}=0,089 \\
& \mathrm{~b}=0,313 \\
& \mathrm{~s}_{\mathrm{b}}=0,038
\end{aligned}
$$




$$
\begin{aligned}
& Z=\frac{0.2513}{\sqrt{0.0008+0.0009+0.0000}} \\
& Z=\frac{0.2513}{\sqrt{0.0017}} \\
& Z=6.0950
\end{aligned}
$$

Oleh karena $Z$ hitung sebesar 6,0950 > 1,96, yang artinya komitmen organisasional merupakan variabel yang memediasi pengaruh budaya organisasi terhadap organizational citizenship behavior pada Dinas Penanaman Modal dan PTSP Kabupaten Badung atau dengan kata lain budaya organisasi berpengaruh secara tidak langsung terhadap organizational citizenship behavior melalui komitmen organisasional.

Hasil penguji mediasi dengan metode VAF dalam penelitian ini telah memenuhi beberapa persyaratan yaitu pertama, pengaruh langsung ditemukan signifikan (c) saat variabel komitmen organisasional (M) belum dimasukkan ke dalam model. Kedua setelah variabel komitmen organisasional (M) dimasukkan ke dalam model, maka pengaruh tidak langsung (a x b) ditemukan pula signifikan. Jalur yaitu a dan b juga signifikan. Ketiga, menghitung Variance Accounted For (VAF) dengan rumus :

$$
\begin{aligned}
\mathrm{VAF} & =\frac{(a \times \mathrm{b})}{(a \times b)+c} \ldots \ldots \ldots \ldots \ldots \ldots \ldots \ldots \ldots \ldots \ldots \ldots \ldots \ldots \ldots \ldots \ldots \ldots \ldots \ldots \ldots \ldots \ldots \ldots \ldots \ldots \ldots \\
\mathrm{VAF} & =\frac{0,803 \times 0,313}{(0,803 \times 0,313)+0,679)}
\end{aligned}
$$

$\mathrm{VAF}=0,269$ atau 26,9 persen dibulatkan menjadi 27 persen. Karena nilai VAF (27 persen) berada di rentang 20 persen hingga 80 persen, maka dapat dikategorikan sebagai pemediasi parsial (partial mediation).

Berdasarkan hasil analisis budaya organisasi berpengaruh positif dan signifikan terhadap organizational citizenship behavior pada Dinas Penanaman Modal dan PTSP Kabupaten Badung. Hasil yang signifikan tersebut disebabkan oleh adanya pegawai yang dituntut dalam menyelesaikan pekerjaannya dengan tepat. Selain itu pegawai senantiasa bekerja dengan menekankan hasil yang maksimal sehingga menyebabkan OCB pegawai menjadi sangat tinggi, artinya semakin baik dan positif budaya yang diterapkan di dalam sebuah organisasi maka semakin tinggi perilaku organizational citizenship behavior pada pegawai. Hal ini menandakan bahwa budaya organisasi mampu menimbulkan perilaku organizational citizenship behavior pada diri pegawai.

Hasil penelitian ini sesuai dengan penelitian sebelumnya yang dilakukan oleh Arifin (2015) menemukan bahwa Budaya Organisasi berpengaruh positif terhadap Organizational Citienship Behavior. Menurut Penelitan Xiaoming dan Junchen (2012) mendapat hasil budaya organisasi berpengaruh positif dan signifikan terhadap OCB. Menurut penelitian Oemar (2013) menyatakan bahwa semakin positif pegawai dalam menilai budaya organisasi dan semakin ia terlibat dalam organisasi yang ada di instansinya, maka kecenderungan organizational citizenship behavior akan meningkat pula. Menurut penelitian Cahyono dkk. (2016) bahwa hasil pengujian budaya organisasi menunjukkan pengaruh yang signifikan terhadap 
organizational citizenship behavior (OCB) Tenaga medis pada RSU Kaliwates Jember. Menurut Maulani dkk, (2015) hasil dari penelitiannya diketahui terdapat pengaruh yang signifikan antara budaya organisasi terhadap organizational citizenship behavior (OCB). Penelitian dari Setyawati (2012) juga menyatakan bahwa budaya organisasi memberikan pengaruh signifikan dan positif terhadap OCB pegawai PT. PLN (Persero) Area Pelayanan dan Jaringan (APJ) Purwoketo. Penelitian Wijaya dan Ahyar (2017) juga menyatakan bahwa budaya organisasi berpengaruh positif dan signifikan terhadap organizational citizenship behavior. Hal ini dapat dilihat dari semakin baik atau kuat budaya organisasi akan semakin meningkatkan organizational citizenship behavior (OCB).

Penelitian Rongga et al. (2001) adanya hubungan yang positif antara budaya organisasi dengan Organizational Citizenship Behavior (OCB), khususnya diperoleh hasil bahwa budaya organisasi yang lebih berorientasi pada pekerja, lebih terbuka dan lebih bersifat konsultatif, pada umunnya dihubungkan dengan sikap yang lebih positif, walaupun hubungan antara budaya dengan Organizational Citizenship Behavior (OCB) tidak terlalu kuat. Erkutlu (2011) menyatakan bahwa budaya organisasi mampu menjelaskan dan memberikan peranan yang penting dalam hubungan antara keadilan organisasi dan Organizational Citizenship Behavior (OCB) dalam suatu organisasi. Penelitian yang dilakukan Mohanty dan Rath (2012) menyatakan bahwa semua dimensi budaya organisasi mempunyai hubungan positif signifikan terhadap organizational citizenship behavior. Dalam penelitian ini dikatakan bahwa budaya organisasi dalam kerangka tertentu dapat membentuk perilaku OCB diantara karyawan.

Berdasarkan hasil analisis budaya organisasi berpengaruh positif dan signifikan terhadap komitmen organisasional pada Dinas Penanaman Modal dan PTSP Kabupaten Badung. Hasil yang signifikan tersebut disebabkan oleh adanya pegawai yang dituntut dalam menyelesaikan pekerjaannya dengan tepat. Selain itu pegawai senantiasa bekerja dengan menekankan hasil yang maksimal sehingga menyebabkan komitmen dari pegawai menjadi lebih tinggi, artinya semakin baik dan positif budaya yang diterapkan di dalam sebuah organisasi maka akan semakin tinggi komitmen pegawai terhadap organisasi. Hal ini menandakan bahwa budaya organisasi mampu menimbulkan komitmen organisasional pada diri pegawai.

Hasil penelitian ini sesuai dengan penelitian sebelumnya yang dilakukan oleh Wibawa dan Putra (2018) dengan judul penelitian pengaruh budaya organisasi terhadap komitmen organisasional dimediasi oleh kepuasan kerja studi pada PT. Bening Badung Bali mendapat hasil bahwa budaya organisasi berpengaruh positif terhadap komitmen organisasional. Budaya organisasi memiliki dampak yang kuat pada perilaku pegawai yang diikuti dengan efektivitas organisasi dan akan memudahkan manajer dalam memahami organisasi dimana mereka bekerja tidak hanya untuk perumusan kebijakan dan prosedur, tetapi untuk memahami perilaku manusia dan pemanfaatan sumber daya manusia dengan cara yang terbaik (Khan dan Rashid, 2015). Hasil analisis data pada penelitian Liu (2009) menunujukkan bahwa pada dimensi budaya organisasi, ditemukan anteseden yang memiliki efek terhadap Komitmen Organisasional, dimana dimensi budaya menunjukkan berbagai tingkat pengaruh positif terhadap Komitmen Organisasional pegawai. Hasil penelitian yang dilakukan oleh Alfiana dan Puspasari (2015) mendapat hasil 
bahwa ada pengaruh yang positif antara budaya organisasi terhadap komitmen organisasi karyawan PT. Sinar Sosro Surabaya. Hasil yang sama juga diperoleh oleh Permatasari dan Supartha (2017) bahwa budaya organisasi memiliki pengaruh yang signifikan terhadap komitmen organisasional karyawan.

Lanjar dkk. (2017) mendapatkan hasil yang sama bahwa budaya organisasi berpengaruh positif terhadap komitmen organisasional. Alvi et al., (2014) meneliti tentang pengaruh budaya organisasi terhadap komitmen organisasional dan kepuasan kerja menunjukan hasil bahwa budaya organisasi berpengaruh positif terhadap komitmen organisasional. Li Yueh Chen (2004) menyatakan bahwa budaya organisasi dan gaya kepemimpinan berpengaruh signifikan positif terhadap komitmen organisasional, kepuasan kerja dan kinerja karyawan. Zain, Ishak, dan Gani (2009) menyatakan Seluruh dimensi budaya organisasi (kerjasama tim, komunikasi, penghargaan, pelatihan, dan pengembangan) memilki pengaruh positif signifikan terhadap komitmen organisasional. Menurut Antonio dan Miguel (2013) adanya penyesuaian yang lebih baik antara persepsi budaya organisasi dan nilainilai yang telah dianut organisasi memiliki hubungan yang positip terhadap komitmen organisasional.

Berdasarkan hasil analisis komitmen organisasional berpengaruh positif dan signifikan terhadap organizational citizenship behavior pada Dinas Penanaman Modal dan PTSP Kabupaten Badung. Hasil yang signifikan tersebut disebabkan oleh adanya pegawai yang bersedia dilibatkan dalam kegiatan kerja demi kepentingan organisasi. Selain itu pegawai merasa dirinya terlibat secara emosional dengan organisasi, artinyabahwa pegawai yang memiliki komitmen organisasional yang tinggi akan dengan sendirinya menimbulkan perilaku organizational citizenship behavior pada pegawai, karena pegawai yang merasa ikut memiliki organisasi, dan bersedia dilibatkan dalam kegiatan organisasi akan bersedia melakukan pekerjaan melebihi tugas-tugas yang diberikan. Hal ini menandakan bahwa komitmen organisasional mampu menimbulkan perilaku organizational citizenship behavior padadiri pegawai.

Hasil penelitian ini sesuai dengan penelitian sebelumnya yang dilakukan oleh Bakhshi et al. (2011) terhadap karyawan dalam perusahaan sektor publik di India. Namun pada penelitian itu pula disebutkan bahwa variabel demografi yang meliputi umur, status perkawinan, jenis kelamin sama sekali tidak berpengaruh terhadap OCB. Qamar (2012) menyebutkan bahwa dimensi OCB secara positif dan signifikan dipengaruhi oleh kepuasan kerja dan komitmen organisasi. Namun, komitmen organisasi memiliki pengaruh lebih kuat terhadap OCB. Hal tersebutlah yang kemudian dapat dikatakan menjadi dasar bahwa OCB (Organizational Citizenship Behavior) dapat dipengaruhi oleh komitmen organisasi. Hasil peneitian yang dilakukan oleh Gautam et al. (2005) mendapatkan hasil bahwa Komitmen Organisasional memiliki pengaruh positif signifikan terhadap Organizational Citizenship Behavior. Hasil penelitian yang dilakukan oleh Chen dan Francesco (2003) mendapatkan bahwa komitmen memiliki pengaruh positif signifikan terhadap OCB. Menurut penelitian Rahmawati (2013) ditemukan bahwa Komitmen Organisasional memberikan pengaruh yang positif terhadap OCB. Penelitian yang dilakukan oleh Sani (2013) yang melibatkan 74 pegawai PT. Bank Syariah Malang menemukan bahwa Komitmen Organisasional berpengaruh positif terhadap OCB. 
Komitmen pegawai yang besar akan lebih sering berbicara secara positif tentang perusahaannya, membantu individu lain dan jauh melebihi harapan normal dalam pekerjaan mereka, selain itu pegawai melakukan pekerjaan dilandasi keinginan dari diri sendiri atau tanpa paksaan (Devi dan Adnyani, 2015).

Ratnaningsih (2013) dalam penelitiannya menemukan bahwa komitmen memberikan pengaruh yang positif terhadap OCB. Penelitian yang dilakukan Rini dkk. (2013) menunjukkan bahwa Komitmen Organisasional memiliki pengaruh positif signifikan terhadap OCB. Maria et al. (2015), Qamar (2012) dan Liu (2009) melakukan penelitian dan menemukan bahwa komitmen organisasi secara signifikan terkait dengan dimensi OCB. Pada dasarnya komitmen organisasi dapat menjadi prediktor untuk OCB sebagai hasil dari Zeinabadi dan Salehi (2011). Moorman et al. (1993), yang menyatakan bahwa komitmen organisasi secara langsung mempengaruhi OCB. Rehan dan Islam (2013) dalam penelitiannya mendapatkan hasil bahwa ketiga bentuk komitmen mempengaruhi OCB secara signifikan.

Berdasarkan hasil Uji Sobel, ditemukan pengaruh yang positif antara variabel budaya organisasi terhadap organizational citizenship behavior melalui variabel mediasi komitmen organisasional pada Dinas Penanaman Modal dan PTSP Kabupaten Badung. Temuan penelitian menandakan hipotesis keempat dalam penelitian ini dapat diterima. Berdasarkan pada hasil uji VAF, menandakan adanya efek mediasi secara parsial. sehingga dapat diartikan bahwa komitmen organisasional mampu memediasi pengaruh budaya organisasi terhadap organizational citizenship behavior dengan kata lain budaya organisasi berpengaruh secara tidak langsung terhadap organizational citizenship behavior melalui komitmen organisasional.

Hasil penelitian ini sesuai dengan penelitian sebelumnya yang dilakukan oleh Wijaya dan Ahyar (2017) mendapatkan hasil bahwa budaya organisasi dan dukungan organisasi terhadap OCB dengan Komitmen Organisasional sebagai variabel mediasi berpengaruh positif dan signifikan. Sedangkan menurut Akhtar dalam (Sanhaji dkk, 2016) menyatakan bahwa budaya organisasi dapat membantu meningkatkan komitmen para karyawan. Kim (2014) menyebutkan bahwa komitmen afektif secara penuh memediasi antara variabel budaya organisasi dan organizational citizenship behavior pada penelitian yang dilakukan di sektor publik Korea Selatan. Mohanty dan Rath (2012) mengatakan karyawan yang merasa bahwa budaya organisasi yang ada pada perusahaan mendukung setiap nilai atau tujuan individu mereka akan lebih nyaman dengan perusahaan sehingga ia akan mendukung setiap rencana-rencana perusahaan dan kemungkinan menunjukkan perilaku yang berada di luar deskripsi pekerjaannya juga semakin kuat. Penelitian yang dilakukan oleh Nandan dan Abdul (2015) menyatakan bahwa komitmen organisasi memediasi pengaruh budaya organisasi terhadap organizational citizenship behavior. Komitmen organisasional mempunyai pengaruh mediasi atau intervening variabel keadilan dan persepsi dukungan organisasi terhadap perilaku OCB dikarenakan jika anggota dalam organisasi memiliki komitmen yang tinggi baik secara afektif, normatif ataupun kotinuan, akan terbentuk hubungan positif antar anggota terhadap organisasi tempat mereka tinggal (Fitriasmi, 2010). Hal ini akan mengakibatkan anggota merasa terikat dengan organisasi yang mendorong 
kecintaanya terhadap organisasi yang kemudian sukarela melakukan perilaku diluar tanggung jawab pekerjaan mereka (extra role) guna bagian dalam memajukan organisasi tempat mereka tinggal terlepas tinggi rendahnya persepsi dukungan organisasi dan keadilan organisasi yang dirasakan oleh anggota organisasi.

Williams et al. (2007) menyimpulkan bahwa ketika komitmen organisasi telah tertanam dalam suatu pola pikir karyawan akan lebih mudah bagi mereka untuk melakukan OCB. Menurut Harwiki (2013), budaya organisasional dan komitmen organisasional berpengaruh positif dan signifikan terhadap OCB. Penelitian Khan dan Rashid (2015) menghasilkan sebuah kesimpulan bahwa Komitmen Organisasional merupakan variabel mediasi yang baik untuk mengetahui hubungan antara budaya organisasi, gaya kepemimpinan dan keadilan organisasi terhadap OCB, karena pada penelitian ini Komitmen Organisasional memiliki pengaruh positif dan signifikan terbesar bila dibandingkan dengan variabel yang lainnya.

\section{SIMPULAN}

Hasil penelitian ini memfokuskan pada kegunaan dan manfaat dari hasil penelitian untuk meningkatkan perilaku Organizational Citizenship Behavior (OCB) pada pegawai Dinas Penanaman Modal dan PTSP Kabupaten Badung melalui budaya organisasi dan komitmen organiasional. Implikasi pertama yaitu diperoleh hasil bahwa Dinas Penanaman Modal dan PTSP Kabupaten Badung menerapkan budaya organisasi dengan baik, dimana pegawai dituntut dalam menyelesaikan pekerjaan dengan tepat dan pegawai senantiasa bekerja dengan menekankan hasil yang maksimal sehingga pegawai mampu meningkatkan kontribusi dalam keberhasilan organisasi. Implikasi yang kedua yaitu diperoleh hasil bahwa tingginya komitmen organisasional pada Dinas Penanaman Modal dan PTSP Kabupaten Badung, dimana pegawai bersedia dilibatkan dalam kegiatan kerja demi kepentingan organisasi sehingga akan timbul perilaku organizational citizenship behavior (OCB) pada pegawai. Implikasi yang ketiga yaitu diperoleh hasil bahwa tingginya perilaku Organizational Citizenship Behavior (OCB) pada Dinas Penanaman Modal dan PTSP Kabupaten Badung, dimana pegawai dengan sukarela membantu rekan kerja yang memiliki masalah lebih dengan pekerjaan dan pegawai datang ke kantor sesuai waktu yang ditetapkan organisasi sehingga pekerjaan akan lebih mudah dan cepat terselesaikan dengan adanya bantuan antar sesama rekan kerja dan pekerjaan tidak akan terganggu dengan pegawai yang datang terlambat.

\section{REFERENSI}

Alfiana, Z. \& Puspasari, D. (2015). Pengaruh Budaya Organisasi terhadap Komitmen Organisasi pada Karyawan PT. Sinar Sosro Surabaya. Jurnal Administrasi Perkantoran, 3(1). 
Alizadeh, Z., Darvishi, S., Nazari, K., \& Emami, M. (2012). Antecedents and consequences of Organizational Citizenship Behaviour (OCB).

Interdisciplinary Journal of Contemporary Research in Business, 3(9), 494505 .

Alvi, H. A., Hanif, M., Shahnawaz, M., Ahmed, R. R. A., \& Vveinhardt, J. (2014). Impact of Organizational Culture on Organizational Commitment and Job Satisfaction. European Journal of Business and Management, 6(27), 30-34.

Antonio, O. ., \& Miguel, A. S. . (2013). Impact of Perceived Corporate Culture on Organizational Commitment. Management Decision, 5(1), 1071-1083.

Ardana, K., Mujiati, N. W., \& Utama, I. W. M. (2012). Manajemen Sumber Daya Manusia (Edisi Pert). Yogyakarta: Graha Ilmu.

Arifin, H. M. (2015). The Influence of Competence, Motivation, and Organizational Culture to High School Teacher Job Satisfaction and Performance. International Education Studies, 8(1), 38-45.

Cahyono, B. C., Sularso, R. A., \& Sumani. (2016). Pengaruh Budaya Organisasi, Kepemimpinan Dan Stres Kerja Terhadap Organizational Citizenship Behavior (OCB) Dengan Kepuasan Kerja Sebagai Variabel Intervening Pada Tenaga Medis RSU Kaliwates Kabupaten Jember. Jurnal Relasi STEI Mandala, 23, 400-413.

Chen, Z. X., \& Francesco, A. M. (2003). The Relationship Between the Three Components of Commitment and Employee Performance in China. Journal of Vocational Behavior, 62(1), 490-510.

Davoudi, S. (2010). Organizational Commitment and Extra Role Behavior: A Survey in Iran's Insurance Industry. Journal of Business Systems, Governance and Ethics, 7(1), 66-75.

Devi, W. S., \& Adnyani, D. (2015). Pengaruh Kepuasan Kerja Karyawan terhadap Komitmen Organisasional dan Organiational Citizeship Behavior (OCB) pada PT. Maharani Prema. E-Jurnal Manajemen Unud, 4(12), 4105-4134.

Erkutlu, H. (2011). The Moderating Role of Organizational Culture in The Relationship Between Organizational Justice and Organizational Citizenship Behaviors. Leadership \& Organization Development Journal, 3(2), 19201925.

Fitriasmi, S. M. (2010). Evaluasi Kesuksesan Aplikasi Knowledge Management dalam Organisasi. Jurnal Dinamika Manajemen, 1(1). 
Gautam, T., Dick, R. Van, Wagner, U., Upadhyay, N., \& Davis, A. J. (2005). Organizational Citizenship Behavior and Organization Commitmen in Nepal. Birmingham: Aston Business School. Aston University.

Ghozali, I. (2013). Aplikasi Analisis Mutivariate Edisi Ketujuh. Semarang: Universitas Diponegoro.

Harper, P. J. (2015). Exploring Forms of Organizational Citizenship Behaviors (OCB): Antecedents and Outcame. Journal of Management and Marketing Research, 18, 1-16.

Harwiki, W. (2013). The Influence of Servant Leadership on Organization Culture, Organizational Commitment, Organizational Citizenship Behavior and Employees' Performance (Study of Outstanding Cooperatives in East Java Province, Indonesia). Journal of Economics and Behavioral Studies, 5, 876-885.

Khan, S. K., \& Rashid, M. Z. (2015). The Mediating Effect of Organizational Commitment in the Organizational Culture, Leadership and Organizational Justice Relationship with Organizational Citizenship Behavior: A Study of Academicians in Private Higher Learning Institutions in Malaysia. International Journal of Business and Social Science, 3(8), 83-91.

Kim, H. (2014). Transformational Leadership, Organizational Clan Culture, Organizational Affective Commitment, and Organizational Citizenship Behavior: A Case of South Korea's Public Sector. Journal of Public Organize Rev, 14, 397-417.

Lakshimi, P. A. V., \& Simartama, N. (2015). Hubungan Antara Iklim Organisasi dengan Perilaku Kewargaan Organisasi pada Pegawai di Perusahaan Ritel. Journal Psikologi Udayana, 2(1), 25-37.

Lanjar, F. A., Hamid, D., \& Muksan, M. D. (2017). Pengaruh Budaya Organisasi Terhadap Komitmen Organisasional dan Kinerja Karyawan (Studi Pada Karyawan Pabrik Gula Kremboong). Jurnal Administrasi Bisnis (JAB), 4l(1).

Liu, Y. (2009). Perceived Organizational Support and Expatriate Organizational Citizenship Behavior: The Mediating Role Of Affective Commitment Towards The Parent Company. Personnel Rev, 38(3), 307-319.

Maria, Z. O., Ernesto, R. E., Pablo, M., \& Gruneiro, C. (2015). Relationship Between Organizational Commitment and Organizational Citizenship Behavior in a Sample of Private Banking Employees. International Journal of Sociology and Social Policy, 35(1), 91-100. 
Maulani, V. H., Widiartanto, \& Dewi, R. S. (2015). Pengaruh Budaya Organisasi dan Komitmen Organisasional Terhadap Kinerja Pegawai Melalui Organizational Citizenship Behavior (OCB) sebagai Variabel Intervening. Jurnal Ilmu Administrasi Bisnis, 4(3), 224-235.

Miharty. (2013). The Influence of Organizational Culture on Job Satisfaction Towards Improving the Quality of Education in University of Riau. Asian Social Science, 9(12), 1-9.

Mira, W. (2012). Pengaruh Servant Leadership terhadap Komitmen Organisasi dan Organization Citizenship Behavior. Jurnal Manajemen, 11(2), 189.

Mohanty, J., \& Rath, B. P. (2012). Influence of Organizational Culture on Organizational Citizenship Behavior: A Three-Sector Study. Global Journal of Business Research, 6(1).

Moorman, C., Deshpande, R., \& Zaltman, G. (1993). Actors Affecting Trustin Market Relationship. Journal of Marketing, 58.

Nandan, T., \& Abdul, M. M. A. (2015). Organizational Culture and Organizational Citizenship Behavior: Mediating Role of Psychological Capital. American International Journal of Social Science, 4(6), 148-156.

Oemar, Y. (2013). Pengaruh Budaya Organisasi, Kemampuan Kerja dan Komitmen Organisasi terhadap OCB Pegawai pada Bappeda Kota Pekanbaru. Jurnal Aplikasi Manajemen, 11(1).

Permatasari, K. C., \& Supartha, W. G. (2017). Pengaruh Kepemimpinan Transformasional, Budaya Organisasi, dan Keadilan Organisasi Terhadap Komitmen Organisasional Pada CV. Megah Food Trading. E-Jurnal Manajemen Unud, 6(8), 4127-4155.

Pourkiani, M., Abdolmajid, F., \& Farhad, G. (2014). Explaining the Relationship Between Organizational Climate, Organizational Commitment and Organizational Citizenship Behavior Among Employess of Khuzestan Gas Company. Indian Journal of Fundamental and Applied Life Sciences, 4(3), 282-290.

Purnamie, T. (2014). Peranan Organizational Citizenship Behavior (OCB) dalam Meningkatkan Kinerja Karyawan. Jember: Mitra Wacana Media.

Qamar, N. (2012). Job Satisfaction and Organizational Commitment as Antecedents of Organizational Citizenship Behavior (OCB). Interdisciplinary Journal of Contemporary Research in Business, 4(7), 103122. 
Rahmawati. (2013). Pengaruh Kepuasan Kerja dan Komitmen Terhadap Organizational Citizenship Behavior (OCB). Media Mahardika, 11(2), 113138.

Ratnaningsih, S. Y. (2013). Pengaruh Kepuasan Kerja dan Komitmen Organisasi Terhadap Organizational Citizenship Behavior (OCB). Media Mahardika, 11(2), 113-138.

Rauf, A. (2014). Perceptions of Organizational Justice as a Predictor of Organizational Citizenship Behavior: An Empirical Study at School is Sri Lanka. European Journal of Business and Management, 6(12), 124-130.

Rehan, M., \& Islam, T. (2013). Relationship Between Organizational Commitment and Citizenship Behavior. World Journal of Management and Behavioral Studies, 1(1), 24-32.

Riady, H. (2009). Meningkatkan Komitmen Karyawan Atas Organisasi Melalui Pengelolaan "Quality of Work Life." Journal of Human Capital, 1(2), 11913.

Rini, D. P., Rusdarti, \& Suparjo. (2013). Pengaruh Komitmen Organisasional, Kepuasan Kerja dan Budaya Organisasi terhadap Organizational Citizenship Behavior (OCB) (Studi Pada PT. Plasa Simpanglima Semarang). Jurnal Ilmiah Dinamika Ekonomi Dan Bisnis, 1(1), 2337-6082 69.

Robbins, S. P., \& Judge, T. A. (2015). Perilaku Organisasi (Edisi 16). Jakarta Selatan: Salemba Empat.

Rongga, J. L., Harrison, G. L., Chow, C. W., \& Wu, A. (2001). Organizational Culture: Association with Commitment, Job Satisfaction, Propensity to Remain and Information Sharing in Taiwan. International Journal of Business Studies, 11(1), 25-44.

Sanhaji, A., \& Dkk. (2016). Pengaruh Keadilan Organisasi dan Budaya Organisasi terhadap Perilaku Kewargaan Organisasi (OCB) melalui Komitmen Organisasi dan Kepuasan Kerja. Jurnal Pendidikan: Teori, Penelitian, Dan Pengembangan, 1(5), 917-926.

Sani, A. (2013). Role of Procedural Justice, Organizational Commitment and Job Satisfaction on Job Perfromance: The Mediating Effects Of Organizational Citizeship Behavior. International Journal of Business and Management, 8(15), 57-67.

Setyawati, E. (2012). Pengaruh Tingkat Kecerdasan Emosi dan Sikap Pada Budaya Organisasi Terhadap Organizational Citizenship Behavior (OCB) Pegawai PT. PLN (Persero) Area Pelayanan dan Jaringan (APJ) Purwokerto. Jurnal Probisnis, 5(2), 42-59. 
Stanley, S. (2013). Kepemimpinan Transformasional dan Organizational Citizenship Behavior Dampaknya Terhadap Kinerja Pegawai KPKNL Provinsi Sulawesi Utara. Jurnal EMBA, 1(3), 356-365.

Sugiyono. (2014). Metode Penelitian Bisnis. Bandung: Alfabeta.

Suwatno, \& Priansa, D. J. (2014). Manajemen Sumber Daya Manusia: Dalam Organisasi Publik dan Bisnis. Bandung: Alfabeta.

Wibawa, I. W. S., \& Putra, M. S. (2018). Pengaruh Budaya Organisasi Terhadap Komitmen Organisasional Dimediasi Kepuasan Kerja (Studi Pada PT. Bening Badung Bali). E-Jurnal Manajemen Unud, 7(6), 3017-3058.

Widodo, S. E. (2015). Manajemen Pengembangan Sumber Daya Manusia. Yogyakarta: Pustaka Pelajar.

Wijaya, N. A., \& Ahyar, Y. (2017). Analisis Pengaruh Budaya Organisasi dan Dukungan Organisasi terhadap Organizational Citizenship Behavior dengan Komitmen Organisasi sebagai Variabel Intervening (Studi pada Pegawai Bagian Antaran PT. Pos Indonesia Processing Center Semarang). Diponegoro Journal of Management, 6(4), 1-13.

Williams, E. S., Rondeau, K. ., \& Fracescutti, L. . (2007). Impact of Culture on Commitment, Satisfaction and Extra Role Behaviour among Canadian ER Physicians. Leadership in Health Services, 20(3), 147-158.

Xiaoming, C., \& Junchen, X. (2012). A Literature Review on Organizational Culture and Corporate Performance. International Journal of Business Administration, 3(2), 29-37.

Zeinabadi, \& Salehi. (2011). Job Satisfaction and Organizational Commitment as Antecedendt of Organizational Citizenship Behavior (OCB) of Teachers in Iran. Journal Social and Behavioral Sciences, 998-1003. 